\title{
Hepatic CEACAM1 over-expression protects against diet-induced fibrosis and inflammation in white adipose tissue
}

\begin{abstract}
Sumona G. Lester ${ }^{1,2}$, Lucia Russo ${ }^{1,2}$, Simona S. Ghanem ${ }^{1,2}$, Saja S. Khuder ${ }^{1,2}$, Anthony M. DeAngelis ${ }^{1,2}$, Emily L. Esakov ${ }^{3}$, Thomas A. Bowman ${ }^{1,2}$, Garrett Heinrich ${ }^{1,2}$, Qusai Y. Al-Share ${ }^{1,2}$, Marcia F. Mclnerney ${ }^{1,3}$, William M. Philbrick ${ }^{4}$ and Sonia M. Najjar ${ }^{1,2 *}$

${ }^{1}$ Center for Diabetes and Endocrine Research, College of Medicine and Life Sciences, University of Toledo, Toledo, OH, USA, ${ }^{2}$ Department of Physiology and Pharmacology, College of Medicine and Life Sciences, University of Toledo, Toledo, $\mathrm{OH}$, USA, ${ }^{3}$ Department of Medicinal and Biological Chemistry, College of Pharmacy and Pharmaceutical Sciences, Toledo, OH, USA, ${ }^{4}$ Section of Endocrinology and Metabolism, Department of Internal Medicine, Yale University School of Medicine, New Haven, CT, USA
\end{abstract}

OPEN ACCESS

Edited by:

Jun Wu,

University of Michigan, USA

Reviewed by:

Zachary Gerhart-Hines,

University of Copenhagen, Denmark

Sandra Kleiner,

Regeneron Pharmaceutical, USA

*Correspondence:

Sonia M. Najjar.

College of Medicine and Life Sciences, University of Toledo, Health Science Campus, 3000 Arlington Avenue, Mail Stop 1009, Toledo, $\mathrm{OH}$ 43614, USA

sonia.najjar@utoledo.edu

Specialty section: This article was submitted to Cellular

Endocrinology, a section of the journal Frontiers in Endocrinology

Received: 19 May 2015

Accepted: 13 July 2015

Published: 03 August 2015

Citation:

Lester SG, Russo L, Ghanem SS, Khuder SS, DeAngelis AM, Esakov EL, Bowman TA, Heinrich G, Al-Share QY, Mclnerney MF, Philbrick WM and Najjar SM (2015) Hepatic CEACAM1 over-expression protects against diet-induced fibrosis and inflammation in white adipose tissue.

Front. Endocrinol. 6:116. doi: 10.3389/fendo.2015.00116
CEACAM1 promotes insulin extraction, an event that occurs mainly in liver. Phenocopying global Ceacam1 null mice $\left(\mathrm{CC}^{-/-}\right)$, C57/BL6J mice fed a high-fat (HF) diet exhibited reduced hepatic CEACAM1 levels and impaired insulin clearance, followed by hyperinsulinemia, insulin resistance, and visceral obesity. Conversely, forced liverspecific expression of CEACAM1 protected insulin sensitivity and energy expenditure, and limited gain in total fat mass by HF diet in L-CC1 mice. Because CEACAM1 protein is barely detectable in white adipose tissue (WAT), we herein investigated whether hepatic CEACAM1-dependent insulin clearance pathways regulate adipose tissue biology in response to dietary fat. While HF diet caused a similar body weight gain in L-CC1, this effect was delayed and less intense relative to wild-type (WT) mice. Histological examination revealed less expansion of adipocytes in L-CC1 than WT by HF intake. Immunofluorescence analysis demonstrated a more limited recruitment of crown-like structures, and qRT-PCR analysis showed no significant rise in TNF $\alpha$ mRNA levels in response to HF intake in L-CC1 than WT mice. Unlike WT, HF diet did not activate TGF- $\beta$ in WAT of L-CC1 mice, as assessed by Western analysis of Smad2/3 phosphorylation. Consistently, HF diet caused relatively less collagen deposition in L-CC1 than WT mice, as shown by Trichrome staining. Coupled with reduced lipid redistribution from liver to visceral fat, lower inflammation and fibrosis could contribute to protected energy expenditure against HF diet in L-CC1 mice. The data underscore the important role of hepatic insulin clearance in the regulation of adipose tissue inflammation and fibrosis.

Keywords: insulin clearance, liver-adipose tissue axis, insulin resistance, steatosis, CEACAM1, fibrosis, inflammation

\footnotetext{
Abbreviations: $\alpha$-Sma, alpha-smooth muscle actin; ApoB48/ApoB100, apolipoprotein B; Col6 $\alpha 3$; alpha 3 chain of collagen 6also known as endotrophin; $\mathrm{Ccl}^{-/-}$, global Ceacam 1 null mouse; CEACAM1, carcinoembryonic antigen-related cell adhesion molecule 1; Ceacam1, gene encoding CEACAM1 protein; Fasn, fatty acid synthase; FAT/CD36, fatty acid translocase/cluster of differentiation protein 36; FATP, fatty acid transporter protein; HF, high-calorie high-fat diet; Hsl, hormone-sensitive lipase; LCC1, mice with liver-specific over-expression of wild-type CEACAM1; Lpl, lipoprotein lipase; L-SACC1, liver-specific S503A CEACAM1 mutant mouse; NEFA, non-esterified fatty acids; RD, regular diet; SREBP-1c, sterol regulatory element-binding protein; TNF $\alpha$, tumor necrosis factor alpha; TGF- $\beta$ transforming growth factor beta.
} 


\section{Introduction}

Carcinoembryonic antigen-related cell adhesion molecule 1 (CEACAM1) promotes insulin extraction in liver to regulate insulin action. This finding is bolstered by the observation that mice with liver-specific inactivation of CEACAM1 (L-SACC1) or with global null deletion of Ceacam1 gene $\left(\mathrm{Cc}^{-/-}\right)$manifest hyperinsulinemia secondary to impaired insulin clearance. This causes insulin resistance in addition to hepatic steatosis $(1-3)$. The latter is mediated by the transcriptional activation of lipogenic genes by sterol regulatory element-binding protein (SREBP-1c) in response to chronically elevated levels of insulin (4). It can also be caused by blunted CEACAM1-mediated downregulation of fatty acid synthase (Fasn) activity under hyperinsulinemic conditions (5).

Both L-SACC1 and $\mathrm{Cc1}^{-/-}$mutant mice also display visceral obesity (1-3). Contributing to this metabolic anomaly, is increased redistribution of hepatic triacylglycerol to white adipose tissue (WAT), in particular that mice are propagated on the C57/BL6J genetic background, which favors redistribution to adipose tissue (6).

We have recently shown that high-fat (HF) intake causes insulin resistance in part by reducing CEACAM1 mRNA and protein levels in liver (7). Conversely, transgenically protecting hepatic CEACAM1 in L-CC1 mice prevented diet-induced insulin resistance and limited hepatic steatosis in response to HF diet (7). Additionally, it blunted the negative effect of HF diet on energy expenditure and spontaneous locomotor activity. This protective effect of hepatic CEACAM1 gain-of-function could be mediated, at least in part, by inducing FGF21, which in turn, enhances fatty acid oxidation in liver $(8,9)$ and increases brown adipogenesis $(10,11)$.

L-CC1 transgenic mice with liver-specific gain-of-function also accumulated less total fat mass than their wild-type (WT) counterparts in response to 4 months of HF intake (7). Because CEACAM1 is barely detectable at the protein level in adipose tissue (12), we hypothesized that extra-adipocytic factors brought about by overexpressing CEACAM1 in liver are involved. To test this hypothesis, we investigated whether altered CEACAM1dependent insulin clearance pathways regulate adipose tissue biology in response to HF diet.

\section{Materials and Methods}

\section{Mice Generation}

As recently described (7), L-CC1 transgenic mice with liverspecific over-expression of FLAG-tagged WT rat CEACAM1 were generated using human apolipoprotein A1 (APOA1) promoter/enhancer element (13), and propagated on the C57/BL6J background (Jackson Laboratories), as described (7). The "minigene" construct was obtained by subcloning the proximal APOA1 promoter $5^{\prime}$ of a Ceacam 1 rat minigene-containing intron 1 into pCMV-3Tag-3A plasmid at Not1 site.

Starting at 2 months of age, male mice were fed ad libitum either a standard diet (12:66:22\% calories from fat:carbohydrate:protein) or a HF diet (45:35:20\% calories from fat:carbohydrate:protein) (Catalog \#D12451, Research Diets). Mice were kept in a 12-h-dark/light cycle. This study was carried out in accordance with the recommendations of the Institutional Animal Care and Utilization Committee (IACUC), which approved all procedures.

\section{Metabolic Parameters}

Mice were fasted overnight and their retro-orbital venous blood drawn at 11:00 hours the following day. Plasma was stored at $-80^{\circ} \mathrm{C}$ until levels of insulin (Linco Research), FFA (NEFA C, Wako), and triacylglycerol (Pointe Scientific Triglyceride, Canton) were assessed. Hepatic triacylglycerol content was measured as previously described $(1,3)$.

\section{Body Composition}

Whole body composition was assessed by nuclear magnetic resonance (NMR; Bruker Optics).

\section{Immunofluorescence of Visceral White Adipose Tissue}

Visceral WAT was formalin-fixed, cut into $2-3 \mathrm{~mm}$ sections, and transferred to Dulbecco's phosphate buffered saline (PBS, Sigma Aldrich) for $48 \mathrm{~h}$ at $4^{\circ} \mathrm{C}$. Adipose tissue was permeabilized in $1 \%$ Triton X-100 (Fisher) in PBS for 10 min before being stained with rat anti-mouse F4/80 (Invitrogen, Carlsbad) to mark macrophages and detected with donkey anti-rat IgG conjugated to Alexa Fluor488 (Invitrogen). Tissues were incubated with primary antibodies overnight at room temperature (RT) in the dark and washed $3 \times$ with staining buffer before being subjected to secondary stain for $2 \mathrm{~h}$ and wash $(3 \times)$ in PBS. Stained samples were then counterstained for $15 \mathrm{~min}$ at RT with $5 \mu \mathrm{M}$ BODIPY 558/568 (Molecular Probes, Inc.) to visualize lipid. Adipose tissue samples were placed directly on a coverslip with buffer and visualized.

\section{Laser-Scanning Confocal Microscopy}

Samples were imaged using a Leica TCS SP5 laser-scanning microscope (Leica Microsystems) equipped with conventional solid state and a Ti-sapphire tunable multi-photon laser (Coherent). Images were acquired in the $3 \mathrm{D} X Y Z$ plane in $2.5 \mu \mathrm{m}$ steps with a $20 \times$ objective (NA 0.70 ) using the sequential scan mode to eliminate any spectral overlap in the individual fluorophores. Specifically, AlexaFluor 488 (Invitrogen) was excited at $488 \mathrm{~nm}$ with collection at 500-558 nm. The BODIPY 558/568 dye (Molecular Probes, Inc.) was excited at $561 \mathrm{~nm}$ and collected at $567-609 \mathrm{~nm}$. Selected images are a 2D representation of the 3D laser-scanning confocal microscopy (LSCM) image $z$-stack, as labeled.

\section{Gomori's Trichrome Staining}

Adipose tissue ( $n=5$ per mouse group) was fixed in $10 \%$ formalin and replaced by $70 \%$ ethanol before undergoing blocking in paraffin. Sections were deparaffinized at $60^{\circ} \mathrm{C}$ and hydrated in deionized water. Antigens were unmasked in Bouin's Fluid at $56^{\circ} \mathrm{C}$ for $45 \mathrm{~min}$. Upon rinsing in deionized water, nuclei were stained with Working Weigert's Iron Hematoxylin at RT for $10 \mathrm{~min}$. Trichrome stain was performed using the Thermo Scientific Richard-Allan Scientific Chromaview-advanced Testing (Cat. No. 87020). In brief, rinsed slides were trichrome stained at RT for $15 \mathrm{~min}$ and dehydrated sequentially in $1 \%$ acetic acid solution for $1 \mathrm{~min}, 95 \%$ ethanol for $30 \mathrm{~s}$, and $100 \%$ ethanol for $1 \mathrm{~min}$ (twice). Sections were 
then cleared in three changes of clearing reagent for $1 \mathrm{~min}$ each and mounted.

\section{Western Analysis}

Tissues were lysed and proteins analyzed by SDS-PAGE followed by immunoprobing with polyclonal antibodies against Fasn ( $\alpha$-Fasn) (Assay Designs), fatty acid translocase/cluster of differentiation protein 36 (FAT/CD36) (Santa Cruz Biotechnology), apolipoprotein B (Chemicon International), and total and phospho-Smad 2 and Smad 3 (Cell Signaling). For normalization, monoclonal antibodies against $\alpha$-actin (Santa Cruz) were used. Blots were incubated with horseradish peroxidase-conjugated anti-goat IgG (Santa Cruz Biotechnology), anti-mouse or antirabbit IgG (Amersham) antibodies, and proteins detected by enhanced chemiluminescence (ECL; Amersham) prior to quantification by densitometry (Image J software).

\section{Semi-Quantitative Real-Time RT-PCR}

Total hepatic RNA was isolated with PerfectPure RNA Tissue Kit $\left(5^{\prime}\right)$, and total adipose tissue RNA was isolated with RNeasy Lipid Tissue Mini Kit (Qiagen) according to the manufacturer's protocol. cDNA was synthesized by ImProm-II ${ }^{\mathrm{TM}}$ Reverse Transcriptase (Promega), using $1 \mu \mathrm{g}$ of total RNA and oligo dT primers (Table 1). cDNA was evaluated with real-time quantitative PCR (Step One Plus, Applied Biosystems). The relative amounts of mRNA were calculated by comparison to the corresponding standards and normalized relative to $18 \mathrm{~S}$.

\section{Statistical Analysis}

Data were analyzed with SPSS software by two-way analysis of variance (ANOVA) or two-tailed Student's $t$-test with GraphPad Prism 4 software. $P<0.05$ was statistically significant.

\section{Results}

\section{Lipid Metabolism}

As expected, HF diet caused hyperinsulinemia and fed hyperglycemia (Table 2), markers of insulin resistance, in WT mice. In support of the positive effect of hyperinsulinemia on lipogenesis (4), qRT-PCR (Table 3) and Western blot analysis showed increased mRNA and protein levels of Fasn, respectively, in the liver of HF-fed WT mice relative to mice fed a regular diet (RD) (Figure 1A). HF diet also induced hepatic mRNA (Table 3) and protein levels of CD36 fatty acid translocase (Figure 1A), in addition to inducing the mRNA level of fatty acid transport protein-1 (Fatp-1) (Table 3). Together with increased lipogenesis, elevated lipid transport could contribute to increased hepatic triacylglycerol content in HF-fed WT mice (Table 2).

Increased production of hepatic triacylglycerol drives output, as supported by elevated plasma apolipoprotein B (ApoB48/ApoB100) protein levels in WT mice (Figure 1B). With fasting plasma triacylglycerol levels being intact (Table 2), it is likely that triacylglycerol was redistributed to the WAT, as expected from mice on the C57/BL6J genetic background that favors substrates partitioning to the adipose tissue (6). Supporting this notion, mRNA levels of Fatp-4 and lipoprotein lipase (Lpl)
TABLE 1 | Real-time PCR primer sequences from mouse genes.

\begin{tabular}{|c|c|c|}
\hline Primer & Forward sequence $\left(5^{\prime}-3^{\prime}\right)$ & Reverse sequence $\left(5^{\prime}-3^{\prime}\right)$ \\
\hline d36 & $\begin{array}{l}\text { TCTTGGCTACAGCAAGGCC } \\
\text { AGATA }\end{array}$ & AGCTATGCATGGAACA \\
\hline atp-1 & TCACTGGCGCTGCTाTGGTT & GGACGTGGCTGTGTATGG \\
\hline Fatp-4 & GTGAGATGGCCTCAGCTATC & GAAGAGGGTCCAGATGCTCT \\
\hline Lpl & $\begin{array}{l}\text { AAGGTCAGAGCCAAGAGAA } \\
\text { GCA }\end{array}$ & $\begin{array}{l}\text { CCAGAAAAGTGAATCTTGACT } \\
\text { TGGT }\end{array}$ \\
\hline Srebp-1c & CATGGATTGCACATT & TCCAGAGAGGAGGCCA \\
\hline $\mathrm{Hsl}$ & GGCT & CAA \\
\hline $\mathrm{F} 4 / 80$ & ACAGAGTITACGTG & CTITGGCTA \\
\hline $\mathrm{TNF} \alpha$ & СТTCTGTCTAC & GAACT \\
\hline Smad7 & GTTGCTGTGAATCTTACGGG & ATCTGGACAGCCTGCA \\
\hline Col6 63 & ACCTAGAGAACGTTACCTCACT & GTCAGCTGAGTCTTGTGCTGT \\
\hline & CGTGGCTATTCCTTCGTTAC & TGCCAGCAGACTCCATCC \\
\hline $18 \mathrm{~S}$ & TTCGAACGTCTGCCCTATCAA & ATGGTAGGCACGGCGACTA \\
\hline
\end{tabular}

that are critical in lipid transport to the adipocyte were elevated in HF-fed relative to RD-fed WT mice (Table 4). This appears to drive adipogenesis, as suggested by higher Srebp-1c mRNA levels (Table 4), and ultimately, increased visceral obesity (Table 2). Elevated mRNA levels of hormone sensitive lipase (Hsl) (Table 4) and the rise in fasting plasma NEFA levels (Table 2) are consistent with increased lipolysis in HF-fed WT mice.

In L-CC1 mice, however, hepatic triacylglycerol content was neither modified by HF intake (Table 2) nor were mRNA levels of Fasn, Fatp-1, and Cd36 (Table 3). Consistent with normal hepatic lipogenesis, plasma ApoB48/ApoB100 protein levels in LCC1 mice were not significantly altered by HF diet (Figure 1B). Moreover, HF did not modulate the mRNA level of genes involved in lipid metabolism in the adipocyte (Lpl, Fatp-4, and Srebp-1c) (Table 4). Consistent with normal fasting plasma NEFA (Table 2), HF did not alter Hsl mRNA levels in the WAT of L-CC1, as it did to WT mice (Table 4).

\section{Visceral Obesity}

High-fat feeding time dependently increased body weight gain in WT mice (Figure 2A). In contrast, it took $\geq 6$ weeks before $\mathrm{HF}$ induced a statistically significant body weight gain in LCC1 (Figure 2A). NMR analysis (Figure 2B) revealed persistently lower fat mass in $\mathrm{L}-\mathrm{CC} 1$ relative to WT mice under normal feeding conditions until $\sim 5$ months of age, at which point this difference became statistically insignificant (Figure 2B, starting at about 11 weeks of experimental feeding). In contrast to total fat mass, visceral (mostly gonadal) and subcutaneous fat mass remained lower in RD-fed L-CC1 than RD-fed WT mice even until 6 months of age (Table 2).

While HF feeding caused an increase in total fat mass relative to $\mathrm{RD}$ feeding in both mouse groups, this effect was delayed (at 5 vs. 3 weeks in L-CC1 vs. WT) (Figure 2B). Furthermore, fat accumulation in L-CC1 mice did not become significantly higher than RD-fed WT until after 7 weeks of HF feeding but remained lower than HF-fed WT even after 4 months of HF, as shown by NMR (Figure 2B), and by ${ }^{1} \mathrm{H}$-magnetic resonance spectroscopy (7). After 4 months of HF diet, visceral fat mass remained lower in L-CC1 than WT mice, while subcutaneous fat mass became comparable in both groups of mice (Table 2). 


\begin{tabular}{|c|c|c|c|c|}
\hline & \multicolumn{2}{|c|}{ WT } & \multicolumn{2}{|c|}{ L-CC1 } \\
\hline & RD & HF & RD & HF \\
\hline Body weight (BW) (g) & $26.0 \pm 0.80$ & $34.0 \pm 1.12^{\star}$ & $24.0 \pm 1.03$ & $34.0 \pm 2.32^{\star}$ \\
\hline Body length $(\mathrm{cm})$ & $9.73 \pm 1.52$ & $10.5 \pm 2.21$ & $9.70 \pm 1.00$ & $10.4 \pm 1.77$ \\
\hline Visceral adipose tissue (\% BW) & $2.45 \pm 0.25$ & $7.55 \pm 0.26^{\star}$ & $1.36 \pm 0.26^{\dagger}$ & $5.76 \pm 0.48^{\star \dagger}$ \\
\hline Brown adipose tissue (\% BW) & $0.39 \pm 0.05$ & $0.39 \pm 0.03$ & $0.34 \pm 0.03$ & $0.36 \pm 0.04$ \\
\hline Subcutaneous fat (\% BW) & $1.76 \pm 0.12$ & $6.23 \pm 0.51^{*}$ & $1.18 \pm 0.13^{\dagger}$ & $5.02 \pm 0.65^{\star}$ \\
\hline Fasting plasma insulin (pM) & $60.0 \pm 1.43$ & $162.0 \pm 8.15^{\star}$ & $58.2 \pm 2.14$ & $78.3 \pm 3.34^{\star \dagger}$ \\
\hline Fed blood glucose (mg/dl) & $120.0 \pm 1.42$ & $150.0 \pm 3.52^{\star}$ & $124.0 \pm 3.25$ & $130.0 \pm 2.82^{\dagger}$ \\
\hline Hepatic triacylglycerol ( $\mu \mathrm{g} / \mathrm{mg}$ protein) & $122.0 \pm 5.00$ & $505.0 \pm 20.4^{*}$ & $135.0 \pm 3.40$ & $152.0 \pm 14.0^{\dagger}$ \\
\hline Fasting plasma triacylglycerol (mg/dl) & $65.4 \pm 3.82$ & $75.3 \pm 4.60$ & $50.3 \pm 3.22^{\dagger}$ & $58.4 \pm 1.42^{\dagger}$ \\
\hline Fasting plasma NEFA (mEq/l) & $0.62 \pm 0.04$ & $0.92 \pm 0.03^{\star}$ & $0.58 \pm 0.02$ & $0.64 \pm 0.04^{\dagger}$ \\
\hline
\end{tabular}

Mice ( $n>8 /$ feeding group/genotype) were fed an HF diet for 4 months starting at 2 months of age. Fat depots were excised and weighed. Intra-abdominal visceral adipose tissue fat refers to combined weight of mesenteric and gonadal fat. The relative mass of fat depots was expressed as percentage of body weight (\% BW).

Values are expressed as mean $\pm S E M$

${ }^{*} P<0.05$ HF vs. RD per genotype.

${ }^{\dagger} P<0.05$ L-CC1 vs. WT per feeding group.

TABLE 3 | Effect of high-fat diet on mRNA levels of lipid metabolism genes in liver.

\begin{tabular}{lcccccc}
\hline & \multicolumn{2}{c}{ WT } & & \multicolumn{2}{c}{ L-CC1 } \\
\cline { 2 - 3 } \cline { 5 - 6 } & RD & HF & & RD & HF \\
\hline Fasn & $1.25 \pm 0.12$ & $3.60 \pm 0.40^{*}$ & & $1.00 \pm 0.20$ & $1.45 \pm 0.25^{\dagger}$ \\
Cd36 & $1.23 \pm 0.11$ & $2.00 \pm 0.30^{*}$ & & $0.67 \pm 0.12$ & $0.86 \pm 0.12^{\dagger}$ \\
Fatp-1 & $1.19 \pm 0.15$ & $2.33 \pm 0.10^{*}$ & & $1.18 \pm 0.05$ & $0.87 \pm 0.08^{\dagger}$
\end{tabular}

Tissue mRNA levels were analyzed in duplicate per mouse $(n \geq 6$ mice/feeding group/genotype).

Values were normalized to $18 S$ and expressed as mean \pm SEM.

${ }^{*} P<0.05$ HF vs. RD per genotype.

${ }^{\dagger} P<0.05$ L-CC1 vs. WT per feeding group.

\section{A Liver}

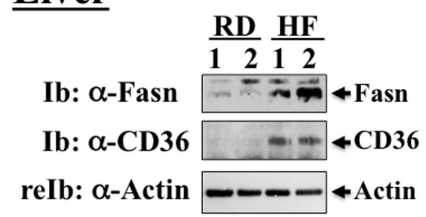

\section{B Plasma}

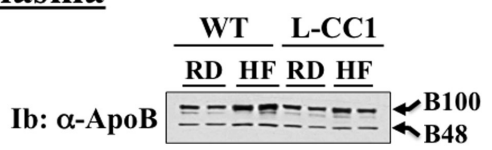

FIGURE 1 | Western analysis of proteins involved in hepatic lipid homeostasis. (A) Liver lysates from wild-type mice fed a regular (RD) or a high-fat diet (HF) for 4 months were analyzed by immunoblotting with $\alpha$-Fasn and $\alpha$-CD36 antibodies, followed by reprobing with $\alpha$-actin for normalization. A representative gel of three different experiments performed on two mice per feeding group is included. (B) Plasma from both WT and L-CC1 mice was diluted and analyzed by $4-10 \%$ gradient SDS-PAGE and immunoblotting with an antibody against apolipoprotein B (ApoB), which recognizes both ApoB48 and ApoB100. A representative gel of two independent experiments performed on two different pairs of mice per feeding group per genotype is included.
TABLE 4 | Effect of 4 months of high-fat diet on mRNA of genes in white adipose tissue.

\begin{tabular}{|c|c|c|c|c|}
\hline & \multicolumn{2}{|c|}{ WT } & \multicolumn{2}{|c|}{ L-CC1 } \\
\hline & RD & HF & RD & HF \\
\hline Fatp-4 & $0.80 \pm 0.10$ & $1.80 \pm 0.22^{*}$ & $0.96 \pm 0.24$ & $0.55 \pm 0.11^{\dagger}$ \\
\hline Lpl & $1.20 \pm 0.21$ & $3.51 \pm 0.30^{*}$ & $1.12 \pm 0.12$ & $1.25 \pm 0.40^{\dagger}$ \\
\hline Srebp-1c & $1.09 \pm 0.13$ & $4.03 \pm 0.70^{\star}$ & $1.26 \pm 0.51$ & $0.94 \pm 0.32^{\dagger}$ \\
\hline $\mathrm{Hsl}$ & $0.49 \pm 0.10$ & $0.80 \pm 0.11^{\star}$ & $0.51 \pm 0.13$ & $0.27 \pm 0.14^{\dagger}$ \\
\hline $\mathrm{F} 4 / 80$ & $8.85 \pm 4.50$ & $21.8 \pm 2.61^{\star}$ & $5.45 \pm 1.22$ & $9.08 \pm 3.01^{\star \dagger}$ \\
\hline $\mathrm{TNF} \alpha$ & $2.75 \pm 1.37$ & $6.56 \pm 0.78^{\star}$ & $3.55 \pm 0.78$ & $3.01 \pm 1.05^{\dagger}$ \\
\hline Smad7 & $11.3 \pm 2.56$ & $1.72 \pm 0.40^{\star}$ & $15.2 \pm 2.05$ & $9.40 \pm 2.04^{\dagger}$ \\
\hline Col6 63 & $0.67 \pm 0.11$ & $1.58 \pm 0.25^{\star}$ & $0.58 \pm 0.17$ & $0.48 \pm 0.13^{\dagger}$ \\
\hline$\alpha-S m a$ & $0.03 \pm 0.01$ & $1.05 \pm 0.33^{\star}$ & $0.06 \pm 0.01$ & $0.19 \pm 0.05^{\dagger}$ \\
\hline
\end{tabular}

Mice ( $n>5$ per feeding group per genotype) were fed an HF diet for 4 months starting at 2 months of age.

Tissue mRNA levels were analyzed in duplicate per each mouse and normalized to $18 \mathrm{~S}$ Values are expressed as mean \pm SEM.

${ }^{*} P<0.05$ HF vs. RD per genotype.

${ }^{t} P<0.05$ L-CC1 vs. WT per feeding group.

\section{Increased Macrophage Recruitment to White Adipose Tissue in Response to High-Fat Diet}

Histological analysis of H\&E stained sections from WAT showed a significant expansion of adipocytes in both groups of mice in response to 4 months of HF intake, but to a lower extent in L-CC1 mice (Figure 3).

Moreover, immunofluorescence analysis of F4/80, a macrophage marker, showed multiple crown-like structures (CLS) containing macrophages in WAT from HF-fed WT mice (Figures 4A,A', green). As previously shown (14), moving through the individual $z$-stack sections shows numerous small pieces of lipid inside the macrophages in CLS (Figures $4 \mathbf{A}, \mathbf{A}^{\prime}$ ), indicating adipocyte degradation in HF-fed WT mice. In contrast, HF-fed L-CC1 mice exhibited minimal CLS formation with little evidence of lipids inside the macrophages in these structures. Consistently, HF diet-induced F4/80 mRNA levels by $~ 2.5$-fold in WT as compared to 1.5 -fold in WAT of L-CC1 mice, and mRNA levels of TNF $\alpha$ adipokine in WT mice (by $\sim 2$-fold), but 


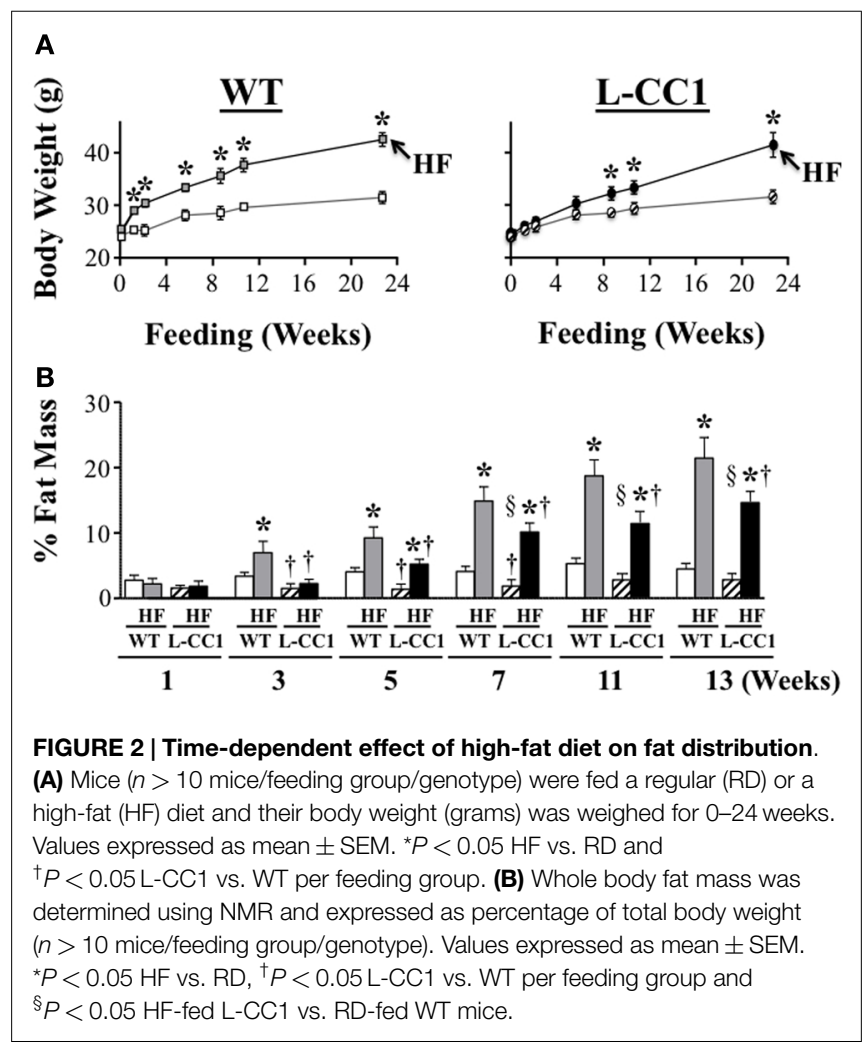

\section{H\&E staining of white adipose tissue}

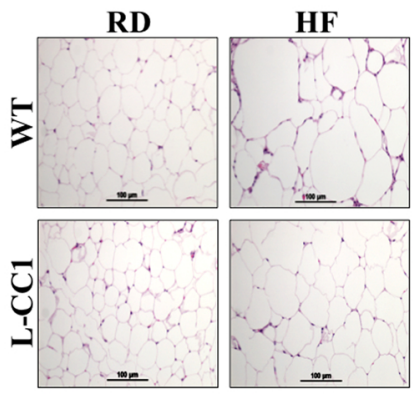

FIGURE 3 | Histological analysis of white adipose tissue. White adipose tissue histology was assessed in H\&E stained sections $(n>4$ mice/feeding group/genotype). Lipid droplets indicate adipocytes' expansion in response to high-fat (HF) relative to regular diet (RD) in both genotypes. Of note, the expansion in L-CC1 was relatively weaker than in WT mice. Representative images from three sections per mouse are shown.

not in L-CC1 mice (Table 4). Together, this demonstrates that protecting hepatic CEACAM1 levels against HF diet limited the development of inflammation in the WAT of L-CC1 mice.

\section{Induction of Fibrosis and TGF- $\beta$ Activation in White Adipose Tissue by High-Fat Diet}

In agreement with reports showing $\mathrm{TNF} \alpha$ inhibition of the expression of Smad 7 (15), a negative regulator of TGF$\beta$-Smad2/3 signaling pathway $(16,17)$, HF markedly repressed



(by 5-fold) the mRNA level of Smad 7 in WT, but not L-CC1 mice (Table 4). Subsequently, HF induced Smad 2 and Smad 3 activation in the WAT of WT, but not L-CC1 mice, as assessed by Western analysis of Smad 2 and Smad 3 phosphorylation (Figure 5A).

In adipose tissue derived from WT, but not L-CC1 mice, HF induced significantly the transcript levels of two main players in fibrosis (Table 4): $\alpha$-smooth muscle actin ( $\alpha$-Sma) (by $\geq 10$-fold) and endotrophin/Col6 63 (by $\sim 2$-fold), a protein that promotes metabolic derangement and fibrosis in adipose tissue (18). This translated into a higher induction of collagen deposition in the WAT of WT than L-CC1 mice by HF feeding, as shown by trichrome staining (Figure 5B).

\section{Discussion}

Phenocopying L-SACC1 mice with liver-specific inactivation of CEACAM1 and global $\mathrm{Cc}^{-/-}$null mice (1-3), HF diet represses hepatic CEACAM1 levels to impair insulin clearance and cause hyperinsulinemia, which in turn, activates de novo lipogenic 


\section{A Western analysis of white adipose tissue}

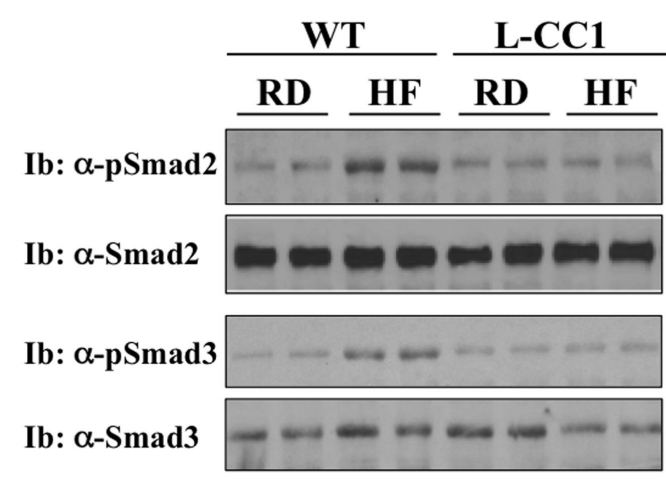

B Trichome staining of white adipose tissue

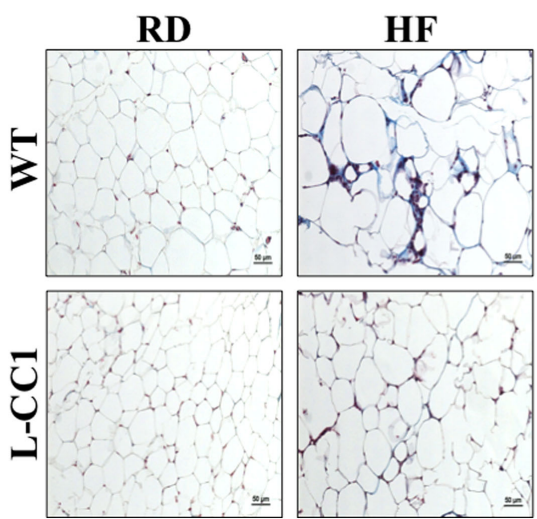

FIGURE 5 | Fibrosis in white adipose tissue. (A) Lysates from white adipose tissue of wild-type (WT) and L-CC1 mice fed a regular (RD) or a high-fat diet (HF) for 4 months were analyzed by immunoblotting with $\alpha$-phospho-Smad 2 and phospho-Smad 3 antibodies followed by reimmunoprobing (relb) with antibodies against total Smad 2 and 3 , respectively, for normalization. A representative gel of three experiments performed on two different mice per feeding group is included. (B) White adipose tissue from five mice/feeding group/genotype was analyzed by trichrome staining to detect collagen deposition. Representative images from three sections per mouse are shown.

pathways and elevates lipid production in liver (7). The current studies show that this drives lipid output (manifested by a rise in plasma ApoB100/ApoB48) and redistribution to WAT to provoke visceral obesity. This is consistent with a positive correlation between liver steatosis, hyperinsulinemia, and high plasma ApoB levels in humans and rodents (19-23). For instance, mice with conditional null mutation of the insulin receptor in liver exhibit impairment of insulin clearance and hepatic insulin resistance with elevated lipogenesis, and a rise in plasma ApoB100/ApoB48 levels in parallel to low plasma triacylglycerol levels and obesity (24).

In support of the important role that reducing hepatic CEACAM1 level plays in the pathogenesis of diet-induced metabolic derangement, protecting hepatic CEACAM1 levels by means of transgenic induction preserves insulin clearance and prevents insulin resistance and hepatic steatosis in response to HF feeding (7). The current studies show that it also causes a delay in the progression of fat accumulation and limits the expansion of adipocytes in response to HF diet. Together, this supports an important role for altered CEACAM1-dependent insulin clearance pathways in the pathogenesis of diet-induced hepatic steatosis and visceral obesity. These findings lend a mechanistic underpinning for the marked reduction of hepatic CEACAM1 observed in insulin-resistant obese subjects (25).

Immunofluorescence analysis showed less recruitment of CLScontaining macrophages to the WAT of L-CC1 and less adipocyte degradation inside these macrophages compared to WT mice. In addition to normal mRNA levels of TNF $\alpha$, an adipokine that blunts insulin action (26), this could explain the protected insulin sensitivity along the liver-WAT axis (7).

In addition to inflammation (26), visceral obesity and insulin resistance are associated with increased fibrosis and activation of TGF- $\beta$ signaling pathways in WAT in rodents $(18,27)$ and humans (28). Consistently, HF feeding induced more collagen deposition and activation of the TGF- $\beta$-Smad $2 / 3$ pathway $(16,17)$ in WT than L-CC1 mice. This could prevent adipose tissue remodeling and contribute to the more metabolic derangement in HF-fed WT mice (29).

In summary, the current studies demonstrate that gain-offunction of CEACAM1 in liver restricts visceral obesity caused by HF diet, and that this is mediated, at least in part, by reducing lipid output from liver and limiting inflammation and fibrosis in WAT. Together with increased FGF21 production (7), this could mediate in part, preserved energy expenditure in $\mathrm{L}-\mathrm{CC} 1$ mice $(7,28,30)$. Because CEACAM1 protein is not produced to a significant extent in WAT (12), preserving adipose tissue biology could be attributed to extra-adipocytic factors caused by inducing CEACAM1 expression in liver. Although the underlying mechanisms are not fully delineated, the current studies provide a proof-of-principle of the importance of hepatic CEACAM1-dependent insulin clearance in the regulation of visceral obesity, and adipose tissue inflammation and fibrosis in response to HF diet.

\section{Author Contributions}

SL researched data, designed experiments, and wrote a first draft of the manuscript, LR, SG, SK, EE, TB, GH, and QA researched data. $\mathrm{AD}$ designed and generated the targeting vector for the generation of the L-CC1 mouse line, screened and propagated the mouse line, and reviewed the manuscript. WP generated the L-CC1 mouse. MM participated in scientific discussions, in detecting CLS, and in the revision of the manuscript. SN was responsible for study design, conceptualization, data analysis and results interpretation, reviewing, and revising the manuscript. SN had full access to all the data of the study and takes responsibility for the integrity and accuracy of data analysis and the decision to submit and publish the manuscript.

\section{Acknowledgments}

This work was supported by grants from the NIH [R01 DK054254, R01 DK083850, and R01 HL112248 (to SN) and R15 DK103196 (to MM)]. The work was also supported in part by the Wolfe Innovation Fund (University of Toledo Foundation). SG is supported by the Middle East Diabetes Research Center. 


\section{References}

1. Park SY, Cho YR, Kim HJ, Hong EG, Higashimori T, Lee SJ, et al. Mechanism of glucose intolerance in mice with dominant negative mutation of CEACAM1. Am J Physiol Endocrinol Metab (2006) 291:E517-24. doi:10.1152/ ajpendo.00077.2006

2. Poy MN, Yang Y, Rezaei K, Fernstrom MA, Lee AD, Kido Y, et al. CEACAM1 regulates insulin clearance in liver. Nat Genet (2002) 30:270-6. doi:10.1038/ ng840

3. DeAngelis AM, Heinrich G, Dai T, Bowman TA, Patel PR, Lee SJ, et al. Carcinoembryonic antigen-related cell adhesion molecule 1: a link between insulin and lipid metabolism. Diabetes (2008) 57:2296-303. doi:10.2337/ db08-0379

4. Osborne TF. Sterol regulatory element-binding proteins (SREBPs): key regulators of nutritional homeostasis and insulin action. J Biol Chem (2000) 275:32379-82. doi:10.1074/jbc.R000017200

5. Najjar SM, Yang Y, Fernstrom MA, Lee SJ, Deangelis AM, Rjaily GA, et al. Insulin acutely decreases hepatic fatty acid synthase activity. Cell Metab (2005) 2:43-53. doi:10.1016/j.cmet.2005.06.001

6. Haluzik M, Colombo C, Gavrilova O, Chua S, Wolf N, Chen M, et al. Genetic background (C57BL/6J versus $\mathrm{FVB} / \mathrm{N})$ strongly influences the severity of diabetes and insulin resistance in ob/ob mice. Endocrinology (2004) 145:3258-64. doi:10.1210/en.2004-0219

7. Al-Share QY, DeAngelis AM, Lester SG, Bowman TA, Ramakrishnan SK, Abdallah SL, et al. Forced hepatic over-expression of CEACAM1 curtails diet-induced insulin resistance. Diabetes (2015) 64:2780-90. doi:10.2337/db141772

8. Inagaki T, Dutchak P, Zhao G, Ding X, Gautron L, Parameswara V, et al. Endocrine regulation of the fasting response by PPARalpha-mediated induction of fibroblast growth factor 21. Cell Metab (2007) 5:415-25. doi:10.1016/j.cmet. 2007.05.003

9. Fisher FM, Chui PC, Nasser IA, Popov Y, Cunniff JC, Lundasen T, et al. Fibroblast growth factor 21 limits lipotoxicity by promoting hepatic fatty acid activation in mice on methionine and choline-deficient diets. Gastroenterology (2014) 147(1073-1083):e1076. doi:10.1053/j.gastro.2014.07.044

10. Emanuelli B, Vienberg SG, Smyth G, Cheng C, Stanford KI, Arumugam M, et al. Interplay between FGF21 and insulin action in the liver regulates metabolism. J Clin Invest (2014) 124:515-27. doi:10.1172/JCI67353

11. Owen BM, Ding X, Morgan DA, Coate KC, Bookout AL, Rahmouni K, et al. FGF21 acts centrally to induce sympathetic nerve activity, energy expenditure, and weight loss. Cell Metab (2014) S1550-4131(1514):320-9. doi:10.1016/j. cmet.2014.07.012

12. Najjar SM. Regulation of insulin action by CEACAM1. Trends Endocrinol Metab (2002) 13:240-5. doi:10.1016/S1043-2760(02)00608-2

13. Walsh A, Ito Y, Breslow JL. High levels of human apolipoprotein A-I in transgenic mice result in increased plasma levels of small high density lipoprotein (HDL) particles comparable to human HDL3. J Biol Chem (1989) 264: 6488-94.

14. Ebke LA, Nestor-Kalinoski AL, Slotterbeck BD, Al-Dieri AG, Lester SG, Russo $\mathrm{L}$, et al. Tight association between macrophages and adipocytes in obesity: implications for adipocyte preparation. Obesity (2014) 22:1246-55. doi:10. 1002/oby.20634

15. Nagarajan RP, Chen F, Li W, Vig E, Harrington MA, Nakshatri H, et al. Repression of transforming-growth-factor-beta-mediated transcription by nuclear factor kappaB. Biochem J (2000) 348(Pt 3):591-6. doi:10.1042/0264-6021: 3480591

16. Nakao A, Afrakhte M, Moren A, Nakayama T, Christian JL, Heuchel R, et al. Identification of Smad7, a TGFbeta-inducible antagonist of TGF-beta signalling. Nature (1997) 389:631-5. doi:10.1038/39369
17. Bitzer M, von Gersdorff G, Liang D, Dominguez-Rosales A, Beg AA, Rojkind M, et al. A mechanism of suppression of TGF-beta/SMAD signaling by NF-kappa B/RelA. Genes Dev (2000) 14:187-97. doi:10.1101/gad.14.2.187

18. Sun K, Park J, Gupta OT, Holland WL, Auerbach P, Zhang N, et al. Endotrophin triggers adipose tissue fibrosis and metabolic dysfunction. Nat Commun (2014) 5:3485-96. doi:10.1038/ncomms4485

19. Elam MB, Wilcox HG, Cagen LM, Deng X, Raghow R, Kumar P, et al. Increased hepatic VLDL secretion, lipogenesis, and SREBP-1 expression in the corpulent JCR:LA-cp rat. J Lipid Res (2001) 42:2039-48.

20. Horton JD, Goldstein JL, Brown MS. SREBPs: activators of the complete program of cholesterol and fatty acid synthesis in the liver. J Clin Invest (2002) 109:1125-31. doi:10.1172/JCI0215593

21. Ginsberg HN, Zhang YL, Hernandez-Ono A. Regulation of plasma triglycerides in insulin resistance and diabetes. Arch Med Res (2005) 36:232-40. doi:10.1016/ j.arcmed.2005.01.005

22. Matikainen N, Manttari S, Westerbacka J, Vehkavaara S, Lundbom N, YkiJarvinen $\mathrm{H}$, et al. Postprandial lipemia associates with liver fat content. J Clin Endocrinol Metab (2007) 92:3052-9. doi:10.1210/jc.2007-0187

23. Vine DF, Takechi R, Russell JC, Proctor SD. Impaired postprandial apolipoprotein-B48 metabolism in the obese, insulin-resistant JCR:LA-cp rat: increased atherogenicity for the metabolic syndrome. Atherosclerosis (2007) 190:282-90. doi:10.1016/j.atherosclerosis.2006.03.013

24. Biddinger SB, Hernandez-Ono A, Rask-Madsen C, Haas JT, Aleman JO, Suzuki $\mathrm{R}$, et al. Hepatic insulin resistance is sufficient to produce dyslipidemia and susceptibility to atherosclerosis. Cell Metab (2008) 7:125-34. doi:10.1016/j. cmet.2007.11.013

25. Lee W. The CEACAM1 expression is decreased in the liver of severely obese patients with or without diabetes. Diagn Pathol (2011) 6:40. doi:10.1186/ 1746-1596-6-40

26. Najjar SM, Russo L. CEACAM1 loss links inflammation to insulin resistance in obesity and non-alcoholic steatohepatitis (NASH). Semin Immunopathol (2014) 36:55-71. doi:10.1007/s00281-013-0407-3

27. Yadav H, Rane SG. TGF-beta/Smad3 signaling regulates brown adipocyte induction in white adipose tissue. Front Endocrinol (2012) 3:35. doi:10.3389/ fendo.2012.00035

28. Divoux A, Tordjman J, Lacasa D, Veyrie N, Hugol D, Aissat A, et al. Fibrosis in human adipose tissue: composition, distribution, and link with lipid metabolism and fat mass loss. Diabetes (2010) 59:2817-25. doi:10.2337/ db10-0585

29. Sun K, Kusminski CM, Scherer PE. Adipose tissue remodeling and obesity. J Clin Invest (2011) 121:2094-101. doi:10.1172/JCI45887

30. Choi MS, Kim YJ, Kwon EY, Ryoo JY, Kim SR, Jung UJ. High-fat diet decreases energy expenditure and expression of genes controlling lipid metabolism, mitochondrial function and skeletal system development in the adipose tissue, along with increased expression of extracellular matrix remodellingand inflammation-related genes. Br J Nutr (2015) 113:867-77. doi:10.1017/ S0007114515000100

Conflict of Interest Statement: The authors declare that the research was conducted in the absence of any commercial or financial relationships that could be construed as a potential conflict of interest.

Copyright (c) 2015 Lester, Russo, Ghanem, Khuder, DeAngelis, Esakov, Bowman, Heinrich, Al-Share, McInerney, Philbrick and Najjar. This is an open-access article distributed under the terms of the Creative Commons Attribution License (CC BY). The use, distribution or reproduction in other forums is permitted, provided the original author(s) or licensor are credited and that the original publication in this journal is cited, in accordance with accepted academic practice. No use, distribution or reproduction is permitted which does not comply with these terms. 